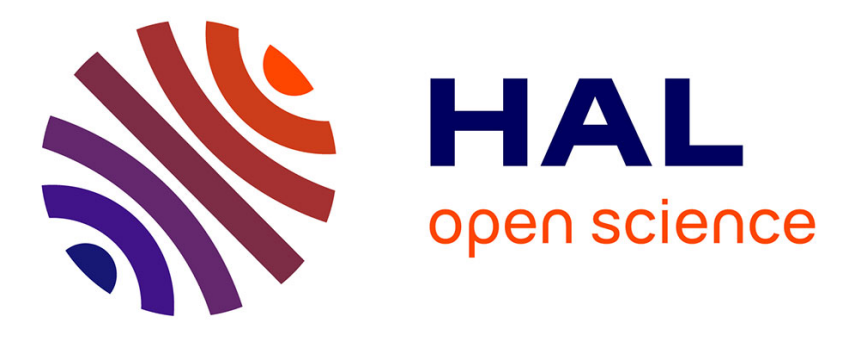

\title{
Modeling of high temperature asymmetric creep behavior of ceramics
}

Eric Blond, Nicolas Schmitt, François Hild, Philippe Blumenfeld, Jacques Poirier

\section{- To cite this version:}

Eric Blond, Nicolas Schmitt, François Hild, Philippe Blumenfeld, Jacques Poirier. Modeling of high temperature asymmetric creep behavior of ceramics. Journal of the European Ceramic Society, 2005, 25 (11), pp.1819-1827. 10.1016/j.jeurceramsoc.2004.06.004 . hal-00020513

\section{HAL Id: hal-00020513 https://hal.science/hal-00020513}

Submitted on 22 Mar 2018

HAL is a multi-disciplinary open access archive for the deposit and dissemination of scientific research documents, whether they are published or not. The documents may come from teaching and research institutions in France or abroad, or from public or private research centers.
L'archive ouverte pluridisciplinaire HAL, est destinée au dépôt et à la diffusion de documents scientifiques de niveau recherche, publiés ou non, émanant des établissements d'enseignement et de recherche français ou étrangers, des laboratoires publics ou privés. 


\title{
Modelling of high temperature asymmetric creep behavior of ceramics
}

\author{
E. Blond ${ }^{\mathrm{a}, 1}$, N. Schmitt ${ }^{\mathrm{a}, *}$, F. Hild ${ }^{\mathrm{a}}$, Ph. Blumenfeld ${ }^{\mathrm{b}}$, J. Poirier $^{\mathrm{b}, 2}$ \\ ${ }^{\text {a }}$ LMT-Cachan (ENS de Cachan, CNRS-UMR 8535, Université Paris 6), 61 avenue du Président Wilson, F-94235 Cachan, France \\ ${ }^{\mathrm{b}}$ CRDM/ARCELOR, Grande Synthe, BP 2508, F-59381 Dunkerque, France
}

\begin{abstract}
An extension of the Bingham-Norton's rheological model accounting for high asymmetric tensile-compressive creep behavior is proposed for ceramics subjected to high temperature loadings. Such behavior is observed in heterogeneous ceramics made of grains having a high creep resistance embedded in a softer glassy phase. Two mechanisms of deformation are introduced: namely, under compressive stresses, grain facets are in contact and transmit the load, whereas under tensile stresses the grains are separated and the glassy matrix transmits the load. It leads to a difference in elastic stiffness and strain rate under tensile and compressive stresses. A new three-dimensional constitutive model is developed considering an additive decomposition of the stress tensor into a positive and negative part. Each stress tensor is the driving force of one mechanism of deformation that is characterized in a classical manner. A simplified identification of the model is performed at high temperature on a bauxite-based refractory, which is used in steel ladle linings. It is shown that for this ceramic few material parameters are sufficient to account for major differences of behavior observed in compression tests and three-point bend tests.
\end{abstract}

Keywords: Creep; Mechanical properties; Refractories; Modelling

\section{Introduction}

Ceramics have well-suited properties making them very attractive for a wide range of high temperature engineering applications (e.g., thermal or chemical barriers in gas turbines, heat engines, heat exchangers, steel ladle's refractory linings). ${ }^{1-3}$ The creep property is an important design criterion for the mechanical stability and lifespan of structures subjected to high temperature. For this reason a considerable work on creep of ceramics exists in the literature. ${ }^{1,4-6}$

Lattice mechanisms of deformation (LMD) and boundary mechanisms of deformation (BMD) are the main mechanisms responsible for the creep behavior of crystalline

\footnotetext{
* Corresponding author. Tel.: +331474028 36; fax: +33147402240. E-mail address: Nicolas.Schmitt@1mt.ens-cachan.fr (N. Schmitt).

${ }^{1}$ Present address: LMSP (Polytech'Orléans, CNRS-UMR 8106, ENSAM Paris), 8 rue Léonard de Vinci, F-45072 Orléans, France.

2 Present address: CRMHT, CNRS, 1D avenue de la Recherche Scientifique, F-45071 Orléans, France.
}

ceramics. ${ }^{1,7,8}$ Defects in the microstructure resulting either from the manufacturing process or nucleated under a macroscopic loading lead also to a damage mechanism of deformation (DMD): creep swelling occurs due to nucleation and growth of pores and/or microcracks. When DMD is added to LMD and BMD, higher creep deformation rates are observed in tension. When a soft creep-resistant amorphous phase binds the grains, local matter transport mechanisms of deformation (MTMD) inside the microstructure leads also to creep deformation. Under compressive stresses, the viscous phase is squeezed between the facets of grains and flows towards voids or lower stressed regions. MTMD depends strongly on the volume content of the glassy phase, the shape of grains and the way in which grains interact ${ }^{6}$ (e.g., no direct contact between the facets, point-contact or surfacecontact). Last, when phase transformations occur, sometimes additional transient time-dependent deformations with low creep resistance exist. ${ }^{6,9,10}$ DMD and MTMD clearly depend on the stress sign that leads to an asymmetric creep behavior. 
The squeezing of the viscous matrix out of the boundary between surfaces of adjacent rigid grains compressed against each other has been modeled by several authors. ${ }^{1-14}$ Dryden $^{14}$ has shown that an asymmetric creep behavior exists between tensile and compressive loads (i.e., the strain rate is higher in tension than in compression). Such behavior is also shown by experimental investigation. ${ }^{15-20}$ For example, Wiederhorn et al. ${ }^{20}$ have found a strain rate ratio of about two orders of magnitude for siliconized silicon carbide. This asymmetric behavior occurs when a glassy phase surrounds the grains. Under tensile stresses, the grains are separated from each other in the loading direction and the macroscopic creep behavior is then dictated by the viscous phase. Under compressive stresses, the grains are pushed together and the boundary layer is squeezed out. It results in a network of contacts between the grains that changes the morphology of the microstructure. DMD leads also to asymmetric creep deformation rates. Ceramics are less sensitive to DMD in compression than in tension, therefore they creep much less. When no specific variable describes the kinetics of damage in the steady-state creep regime, under tensile load, an artificial increase of the stress exponent in the classical Norton's law is observed that is associated with the onset of cavitation. ${ }^{6,15}$

The asymmetric one-dimensional tensile-compressive behavior has also been modeled. For example, Wereszezak et al. ${ }^{16}$ proposed a creep strain rate defined as an additive combination of Norton's law creep rate with $n=1$ exponent and a creep strain rate depending on a function of stress that is the product of exponential and linear functions of stress. In this model, the smooth change of the tensile-compressive regimes is advantageous from a numerical point of view. Although three-dimensional time-dependent inelastic models have been widely developed for metals, ${ }^{21}$ soils and rocks, ${ }^{22}$ few specific models exist for ceramic materials. Chuang et al. $^{23}$ propose constitutive equations in a power-law creep form based on asymmetric tensile-compression creep responses under uniaxial creep. The asymmetric response is governed by the sign of the largest principal stress in magnitude. Lim et al. ${ }^{24}$ have pointed out that this model does not seem plausible when the difference in magnitude of tensile and compressive principal stresses is very small. Consequently, they propose that the viscoplastic strain rate is the sum of three viscoplastic strain rates developed, respectively, by the three principal stresses, each strain rate depending on the sign of the corresponding principal stress. However, for numerical reasons due to errors introduced by an infinitesimal rotation relative to the principal axis direction, they also introduce equations to compute the small shear creep deformation rates.

In the next section, a new phenomenological model is proposed for composite ceramics having a highly asymmetric creep behavior in tension and compression. One key aspect of the model is that the pure tensile and compressive behaviors are completely uncoupled so that the identification of the material parameters is easy to perform. The model is then used to predict the thermomechanical behavior of a bauxite refractory used in steel ladle refractory linings that work at high-temperature near its pyrometric cone equivalent (PCE). ${ }^{25}$ The experimental set-up of compression and threepoint bending are presented and some results are shown. An identification of the model is given and a comparison with experimental data is performed.

\section{Asymmetric thermomechanical model}

The model is developed within the framework of continuum thermodynamics with state variables. ${ }^{21,26,27}$ For sake of simplicity, infinitesimal strains are considered, but a finitestrain formulation of the model is possible. No viscoplastic dilatancy is assumed to occur during creep deformation due to void or microcrack nucleation and/or growth. Moreover, if the composite ceramic contains a high content of a soft glassy phase, mass conservation of the elementary volume is assumed. Otherwise, the model is only valid for the skeleton and the development should be performed in the framework of the thermomechanics of porous continua. ${ }^{28}$

Under multiaxial loading, when sintering or densification mechanisms do not occur, the creep behavior of polycrystalline metals is only driven by deviatoric stresses. Consequently, the kinetic law of viscoplastic models is dependent on the second stress invariant. ${ }^{21}$ For geomaterials (e.g., concrete, soil and rock), the creep behavior depends on the average pressure too, so that several viscoplastic models have been developed. ${ }^{22}$ Unfortunately, none of these models is able to describe the big difference in creep behavior observed between tension and compression for multiphase ceramics such as refractories.

To account for this high asymmetry, one solution consists in introducing two separate mechanisms responsible for the deformation in the constitutive model, one activated under tensile loadings (i.e., matrix creep) and the other under compressive loadings (i.e., grains creep). This can be achieved by an additive decomposition of the stress tensor into a positive and negative part as previously proposed to characterize the unilateral behavior of damaged materials due to openingclosure of microcracks. ${ }^{29-31}$

\section{Constitutive equations}

Let $\boldsymbol{\varepsilon}$ be the total strain tensor. Assuming small strains, the total strain tensor is described by the symmetric part of the gradient of the displacement vector $\boldsymbol{u}=\boldsymbol{u}(\boldsymbol{X})$ with respect to the spatial position $\boldsymbol{X}$ of the material point

$\boldsymbol{\varepsilon}=\frac{1}{2}\left[\frac{\partial \boldsymbol{u}}{\partial \boldsymbol{X}}+\left(\frac{\partial \boldsymbol{u}}{\partial \boldsymbol{X}}\right)^{\mathrm{T}}\right]$

where $\mathrm{T}$ denotes the transposition operator. Moreover, the total strain is the sum of a thermo-elastic strain and a 
viscoplastic strain

$\varepsilon=\varepsilon_{\text {th-e }}+\varepsilon_{\mathrm{vp}}$

where $\boldsymbol{\varepsilon}_{\text {th-e }}$ is the thermo-elastic strain tensor and $\boldsymbol{\varepsilon}_{\mathrm{vp}}$ the viscoplastic strain tensor, respectively. To introduce an asymmetric behavior depending on the stress sign, the stress tensor $\boldsymbol{\sigma}$ is decomposed into a positive part $\langle\boldsymbol{\sigma}\rangle$ and a negative part $\langle-\sigma\rangle$ in the principal frame 29,30

$\sigma=\langle\sigma\rangle-\langle-\sigma\rangle$

For composite ceramics containing a soft creep matrix, an asymmetric elastic stiffness exists, i.e., the material is stiffer in compression when the oxide grains are in contact than in tension when the soft matrix separates the grains. For the sake of simplicity, the thermo-elastic behavior of the material remains isotropic with different elastic properties in tension and in compression. The linear thermo-elastic constitutive law is characterized by the specific enthalpy $\Psi^{*}$, which is function of $\langle\sigma\rangle,\langle-\sigma\rangle$ and the temperature $T$. The specific enthalpy is assumed entirely recoverable so that no energy is stored

$$
\begin{aligned}
\psi^{*}(\boldsymbol{\sigma}, T)= & \frac{1}{2 \rho E_{\mathrm{t}}(T)}\left[\left(1+v_{\mathrm{t}}(T)\right)\langle\boldsymbol{\sigma}\rangle:\langle\boldsymbol{\sigma}\rangle-v_{\mathrm{t}}(T) \operatorname{Tr}(\langle\boldsymbol{\sigma}\rangle)^{2}\right] \\
& +\frac{1}{2 \rho E_{\mathrm{c}}(T)}\left[\left(1+v_{\mathrm{c}}(T)\right)\langle-\boldsymbol{\sigma}\rangle:\langle-\boldsymbol{\sigma}\rangle\right. \\
& \left.-v_{\mathrm{c}}(T) \operatorname{Tr}(\langle-\boldsymbol{\sigma}\rangle)^{2}\right] \\
& +\alpha(T)\left(T-T_{0}\right) \boldsymbol{I}: \boldsymbol{\sigma}+\psi_{\mathrm{th}}^{*}(T)
\end{aligned}
$$

where $\rho$ is the mass density; $E_{\mathrm{c}}(T), v_{\mathrm{c}}(T)$ are Young's modulus and Poisson's ratio in compression; $E_{\mathrm{t}}(T)$ and $v_{\mathrm{t}}(T)$ are Young's modulus and Poisson's ratio in tension; $\alpha(T)$ is the coefficient of thermal expansion; $T_{0}$ is the reference temperature; ' $:$ ' indicates the contraction with respect to two indices; $\boldsymbol{I}$ is the second rank identity tensor. When no phase transformation occurs and the heat capacity $C$ is constant, the thermal contribution $\psi_{\mathrm{th}}^{*}(T)$ is given by

$\psi_{\mathrm{th}}^{*}(T)=C\left[T \ln \left[\frac{T}{T_{\phi}}\right]-\left(T-T_{\phi}\right)\right]$

where $C$ is the specific heat capacity. It can be noted that even though $\langle\sigma\rangle$ is not differentiable, $\Psi^{*}$ has well-defined first derivatives with respect to $T$ and $\sigma$. The law of thermoelasticity is derived from Eq. (4) by the partial derivation of $\Psi^{*}$ with respect to the stress tensor $\sigma$

$$
\begin{aligned}
\varepsilon_{\mathrm{th}-\mathrm{e}}= & \frac{1+v_{\mathrm{t}}(T)}{E_{\mathrm{t}}(T)}\langle\boldsymbol{\sigma}\rangle-\frac{v_{\mathrm{t}}(T)}{E_{\mathrm{t}}(T)} \operatorname{Tr}(\langle\boldsymbol{\sigma}\rangle) \\
& -\frac{1+v_{\mathrm{c}}(T)}{E_{\mathrm{c}}(T)}\langle-\boldsymbol{\sigma}\rangle+\frac{v_{\mathrm{c}}(T)}{E_{\mathrm{c}}(T)} \operatorname{Tr}(\langle-\boldsymbol{\sigma}\rangle) \\
& +\alpha(T)\left(T-T_{0}\right) \boldsymbol{I}
\end{aligned}
$$

Note that the thermal expansion in Eq. (6) is isotropic and is not dependent on the sign of stress. The asymmetric viscoplastic behavior is obtained by extension of the classical
Norton's law proposed for power-law steady-state creep. ${ }^{21}$ Let us define the deviatoric stresses of the positive and negative parts of the stress tensor, $\boldsymbol{S}^{+}$and $\boldsymbol{S}^{-}$, respectively

$\boldsymbol{S}^{+}=\langle\boldsymbol{\sigma}\rangle-\frac{1}{3} \operatorname{Tr}(\langle\boldsymbol{\sigma}\rangle) \boldsymbol{I}$ and $\boldsymbol{S}^{-}=\langle-\boldsymbol{\sigma}\rangle-\frac{1}{3} \operatorname{Tr}(\langle-\boldsymbol{\sigma}\rangle) \boldsymbol{I}$

The two deviatoric stresses are related by

$S=S^{+}-S^{-}$

where $S$ is the deviatoric part of the stress tensor $\sigma$. Let us define the corresponding von Mises equivalent stresses $\mathrm{J}_{2}{ }^{+}$and $J_{2}^{-}$

$J_{2}^{+}=\sqrt{\frac{3}{2} S^{+}: S^{+}}$and $J_{2}^{-}=\sqrt{\frac{3}{2} S^{-}: S^{-}}$

The asymmetric domain of thermo-elasticity in the stress space is limited by the multiple yield-surfaces defined by the criteria $f^{+}(\langle\boldsymbol{\sigma}\rangle)=0$ and $f^{-}(\langle-\boldsymbol{\sigma}\rangle)=0$. It is assumed that the yield functions depend only on the deviatoric parts of the stress tensor

$f^{+}\langle\boldsymbol{\sigma}\rangle=J_{2}^{+}-\sigma_{y}^{\mathrm{t}}(T)$ and $f^{-}\langle-\sigma\rangle=J_{2}^{-}-\sigma_{y}^{\mathrm{c}}(T)$

where $\sigma_{y}^{\mathrm{c}}(T)$ and $\sigma_{y}^{\mathrm{t}}(T)$ are the threshold stress in pure compression and pure tension, respectively, above which viscoplasticity is active. Both parameters are positive and dependent on the temperature. By assuming that (i) the rate of viscoplastic strain is a power-law function of the deviatoric stress, (ii) different kinetics of flow exist in tension and in compression, (iii) no viscoplastic dilatancy, the viscoplastic strain rate can be written as

$$
\begin{aligned}
\dot{\boldsymbol{\varepsilon}}_{\mathrm{vp}}= & \frac{3 S^{+}}{2 J_{2}^{+}}\left(\frac{\left\langle J_{2}^{+}-\sigma_{y}^{\mathrm{t}}(T)\right\rangle}{K_{\mathrm{t}}(T)}\right)^{n_{\mathrm{t}}(T)} \\
& -\frac{3 S^{-}}{2 J_{2}^{-}}\left(\frac{\left\langle J_{2}^{-}-\sigma_{y}^{\mathrm{c}}(T)\right\rangle}{K_{\mathrm{c}}(T)}\right)^{n_{\mathrm{c}}(T)}
\end{aligned}
$$

where $n_{\mathrm{t}}(T), K_{\mathrm{t}}(T)$, and $n_{\mathrm{c}}(T), K_{\mathrm{c}}(T)$ are material parameters associated to the tensile activated creep and compressive activated creep, respectively. This model is thermodynamically admissible when Clausius-Duhem's inequality is satisfied. When Fourier's law is used, this inequality reads

$\sigma: \dot{\varepsilon}-\rho(\dot{\psi}+s \dot{T})-\lambda \operatorname{grad}\left(\frac{\operatorname{grad} T}{T}\right) \geq 0$

where $\psi$ is the specific free energy, $\lambda$ is the coefficient of thermal conductivity and $s$ is the specific entropy. Eq. (12) is satisfied when the intrinsic dissipation $D_{\mathrm{i}}=\sigma: \dot{\boldsymbol{\varepsilon}}_{\mathrm{vp}} \geq 0 .{ }^{21}$ Replacing $\dot{\boldsymbol{\varepsilon}}_{\mathrm{vp}}$ by Eq. (11), $\boldsymbol{\sigma}$ by Eq. (3), the intrinsic dissipation $D_{\mathrm{i}}$ reduces to

$$
\begin{aligned}
D_{\mathrm{i}}= & \phi^{+} \boldsymbol{S}^{+}: \boldsymbol{S}^{+}+\phi^{-} \boldsymbol{S}^{-}: \boldsymbol{S}^{-} \\
& +\left(\phi^{+}+\phi^{-}\right) \frac{\operatorname{Tr}(\langle\boldsymbol{\sigma}\rangle) \operatorname{Tr}(\langle-\sigma\rangle)}{3}
\end{aligned}
$$


Table 1

One-dimensional constitutive equations of the asymmetric thermo-elastic-viscoplastic model

\begin{tabular}{ll}
\hline Thermo-elastic law & $\sigma=E^{*}\left(\varepsilon-\varepsilon_{\mathrm{vp}}-\alpha\left(T-T_{0}\right)\right) \quad$ with $\quad E^{*}=E_{\mathrm{c}}(T) \frac{\langle-\sigma\rangle}{-\sigma}+E_{\mathrm{t}}(T) \frac{\langle\sigma\rangle}{\sigma} \quad$ when $\quad \sigma \neq 0$ \\
Domain of thermo-elasticity & $\langle\sigma\rangle-\sigma_{y}^{\mathrm{t}}(T) \leq 0 \quad$ and $\quad\langle-\sigma\rangle-\sigma_{y}^{\mathrm{c}}(T) \leq 0$ \\
Kinetic law & $\dot{\varepsilon}_{\mathrm{vp}}=\left(\frac{\left\langle\langle\sigma\rangle-\sigma_{y}^{\mathrm{t}}(T)\right\rangle}{K_{\mathrm{t}}(T)}\right)^{n_{\mathrm{t}}(T)}-\left(\frac{\left\langle\langle-\sigma\rangle-\sigma_{y}^{\mathrm{c}}(T)\right\rangle}{K_{\mathrm{c}}(T)}\right)^{n_{\mathrm{c}}(T)}$
\end{tabular}

where

$$
\begin{aligned}
\phi^{+} & =\frac{3}{2 J_{2}^{+}}\left(\frac{\left\langle f^{+}\left(S^{+}\right)\right\rangle}{K_{\mathrm{t}}(T)}\right)^{n_{\mathrm{t}}(T)} \text { and } \\
\phi^{-} & =\frac{3}{2 J_{2}^{-}}\left(\frac{\left\langle f^{-}\left(\boldsymbol{S}^{-}\right)\right\rangle}{K_{\mathrm{c}}(T)}\right)^{n_{\mathrm{c}}(T)}
\end{aligned}
$$

Since both $\phi^{+}, \phi^{-}, \operatorname{Tr}(\langle\sigma\rangle)$ and $\operatorname{Tr}(\langle-\sigma\rangle)$ are positive, it is straightforward to show that $D_{\mathrm{i}} \geq 0$.

\section{Comments}

\subsection{One-dimensional model and identification of the material parameters}

The one-dimensional model can be easily derived from the constitutive equations. The set of equations are given in Table 1. The associated rheological model is shown in Fig. 1. When the material is loaded either in tension or in compression, then the model reduces to the classical Bingham-Norton's model, which is widely used to identify the elasto-viscoplastic behavior of ceramics at high temperature. . $^{1,2,7}$

One great advantage of the proposed model is that when both results of pure tensile and compression tests are available, the two sets of parameters $\left(E_{\mathrm{t}}, v_{\mathrm{t}}, \sigma_{y}^{\mathrm{t}}, K_{\mathrm{t}}, n_{\mathrm{t}}\right)$ and $\left(E_{\mathrm{c}}, v_{\mathrm{c}}\right.$, $\left.\sigma_{y}^{\mathrm{c}}, K_{\mathrm{c}}, n_{\mathrm{c}}\right)$ can be determined separately by using creep tests or tests with several loading paths, thereby making easier the identification. When tensile tests are replaced by bend tests, the identification is divided into two steps. First, the identification of the parameters set $\left(E_{\mathrm{c}}, v_{\mathrm{c}}, \sigma_{y}^{\mathrm{c}}, K_{\mathrm{c}}, n_{\mathrm{c}}\right)$ is to be carried out by using the compressive tests. During this identification, the tensile parameters of the model are not activated, and the identification is straightforward. In the second step, the bend test is simulated by finite element computations to identify the tensile contribution of the viscous strain and the second set $\left(E_{\mathrm{t}}, v_{\mathrm{t}}, \sigma_{y}^{\mathrm{t}}, K_{\mathrm{t}}, n_{\mathrm{t}}\right)$ can be determined.

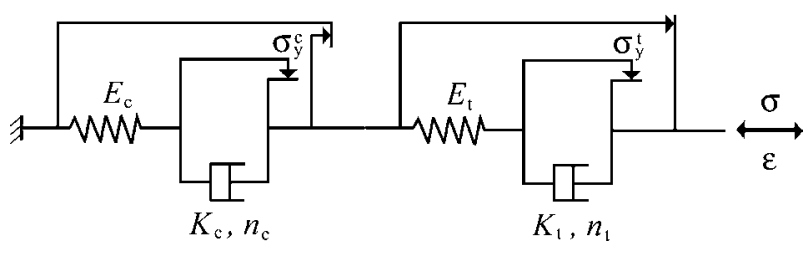

Fig. 1. Rheological model.

\subsection{Numerical resolution}

Knowing the state of variables $\left(\boldsymbol{\varepsilon}_{n}, \boldsymbol{\sigma}_{n}, \boldsymbol{\varepsilon}_{\mathrm{vp}, n}, \boldsymbol{T}_{n}\right)$ at time $t_{n}$, to solve the global equilibrium of the finite discretization of the structure and to update the internal variables at time $t_{n+1}=t_{n}+\Delta t_{n}$, the local integration of the constitutive equations at each Gauss point and the computation of the local consistent Jacobian operator must be performed. These calculations are carried out by using the numerical algorithm developed by Benallal et al. ${ }^{32}$ For the time increment $\Delta t_{n}$, the conditions $\Delta \varepsilon=\varepsilon_{n+1}-\varepsilon_{n}, \Delta T_{n}=T_{n+1}-T_{n}$ are introduced in the local algorithm and the variables $\left(\sigma_{n+1}\right.$, $\boldsymbol{\varepsilon}_{\mathrm{vp}, n+1}$ ) are computed at time $t_{n+1}$. Consequently, Eq. (6) is rewritten as

$\boldsymbol{\sigma}-\boldsymbol{H}\left(\boldsymbol{\varepsilon}_{n+1}, \boldsymbol{\varepsilon}_{\mathrm{vp}, n+1}, T_{n+1}\right)=0$

and the time-discretization of Eq. (11) is obtained through an implicit finite differences scheme using the $\theta$-method

$\Delta \boldsymbol{\varepsilon}_{\mathrm{vp}, n}-\boldsymbol{G}\left(\boldsymbol{\sigma}_{n+\theta}, \boldsymbol{\varepsilon}_{n+\theta}, \boldsymbol{\varepsilon}_{\mathrm{vp}, n+\theta}, T_{n+\theta}\right)=0$

where $(\cdot)_{n+\theta}=\theta(\cdot)_{n+1}-(1-\theta)(\cdot)_{n}$. First the entire increment is assumed to be thermo-elastic and the stresses are computed with Eq. (15) where $\boldsymbol{\varepsilon}_{\mathrm{vp}, n+1}=\boldsymbol{\varepsilon}_{\mathrm{vp}, n}$. If the elastic prediction satisfies the conditions $f_{n+1}^{+} \leq 0$ and $f_{n+1}^{-} \leq 0$, then the local procedure is completed and the corresponding consistent Jacobian operator $\boldsymbol{J}$ defined by $\delta \boldsymbol{\sigma}=\boldsymbol{J}: \delta \boldsymbol{\varepsilon}$ is given by $\boldsymbol{J}=\boldsymbol{E}$ where $\boldsymbol{E}$ is the current elastic stiffness tensor. Otherwise when either $f_{n+1}^{+}>0$ or $f_{n+1}^{-}>0$, the viscoplastic correction is calculated by solving the set of equations (Eqs. (15) and (16)) using a Newton-Raphson procedure. When the local integration has converged, the corresponding consistent Jacobian operator $\boldsymbol{J}$ is determined numerically by letting variables vary slightly around the converged solution at time $t_{n+1}$. This numerical scheme is implemented in the ABAQUS finite element $\operatorname{code}^{33}$ by using a UMAT routine.

\subsection{Possible extensions of the model}

As the model is built in the framework of an additive stress tensor decomposition, it can be extended to account for hardening effects. It is also possible to describe the breakdown observed in power-law creep for some ceramics. However, one must keep in mind that further developments of the model increase the number of material parameters to identify and consequently the experimental data to collect. Therefore, such extension is limited to ceramics with high-added value used for high technology design. 


\section{Application to a bauxite-based refractory ceramic}

An identification of the material parameters is performed for a high-alumina-content refractory. Refractory bauxitebased bricks are used in working linings of steel ladles. In contact with molten steel and slag, they are subjected to intense loadings, namely thermal stresses due to high temperatures varying between $900^{\circ} \mathrm{C}$ on the back face to $1650^{\circ} \mathrm{C}$ on the inner face and corrosion by slag that impregnates the material. The modelling of the thermomechanical behavior of these bricks has been carried out to examine the degradation by thermal spalling that occurs a few centimeters away from the hot surface. ${ }^{18,34}$ In this section, only the identification procedure and the corresponding results are discussed as an application of the model proposed herein.

\section{Composition of bauxite refractory}

The raw material has a heterogeneous microstructure made of oxide grains with sizes varying from a few millimeters to a few micrometers and a vitreous phase (Fig. 2). Most grains are coarse bauxite particles composed of large corundum crystals surrounded by mullite, aluminum titanate and a glassy phase. The matrix contains fine alumina and bauxite particles, a phosphate bond (aluminum phosphates or/and phosphoric acid) and usually a small amount of clay. The chemical composition of the unfired and chemically bonded bauxite refractory is given in Table 2 .

In situ refractories have a more complex composition and microstructure due to phase transformations occurring after the first heating and impregnation by molten slag (e.g., in steel ladles). The worn bricks taken from the lining of a steel ladle show that the slag impregnation boundary is close to the temperature $1250{ }^{\circ} \mathrm{C} .{ }^{18}$ For this reason, the mechanical
Table 2

Example of composition of a bauxite refractory

\begin{tabular}{llll}
\hline Chemical composition (wt.\%) & Mineralogy (wt.\%) & \\
\hline $\mathrm{Al}_{2} \mathrm{O}_{3}$ & $85-87$ & Corundum & $70-80$ \\
$\mathrm{SiO}_{2}$ & $6.5-8.0$ & Mullite & $3-10$ \\
$\mathrm{Fe}_{2} \mathrm{O}_{3}$ & $1.2-1.8$ & Vitreous phase & $15-20$ \\
$\mathrm{TiO}_{2}$ & $3.8-4.5$ & Tielite & $4-7$ \\
$\mathrm{CaO}$ & $0.15-0.3$ & Rutile & $<1$ \\
\hline
\end{tabular}

behavior of the unused brick is characterized at the temperatures 1000 and $1250{ }^{\circ} \mathrm{C}$ corresponding to the un-impregnated zone. In this temperature range, the solid skeleton is embedded by an intergranular glassy phase whose content varies in the $8-40 \mathrm{wt} . \%$ range. This viscous phase is due to the presence of silica, in the bounding phase, which has a low melting temperature in comparison with that of alumina grains.

\section{Experimental set-up}

The experimental set-up uses an induction furnace with a controlled atmosphere, and two interchangeable devices allowing us to perform three-point bend tests on prismatic samples $(50 \mathrm{~mm} \times 50 \mathrm{~mm} \times 150 \mathrm{~mm})$ with a span of $125 \mathrm{~mm}$ or compression tests on cylindrical samples $(25 \mathrm{~mm}$ in diameter and $60 \mathrm{~mm}$ in height). A temperature range of $20-1600^{\circ} \mathrm{C}$ can be achieved. Each sample is heated up to the testing temperature with a rate of $200^{\circ} \mathrm{C} / \mathrm{h}$ and maintained for $2 \mathrm{~h}$ to homogenize the temperature of the sample before the mechanical load is applied. Furthermore, this temperature stage allows us to ensure that no phase transformation occurs during the mechanical load inducing additional strains. An LVDT sensor is used to measure the deflection or the length reduction of the sample.

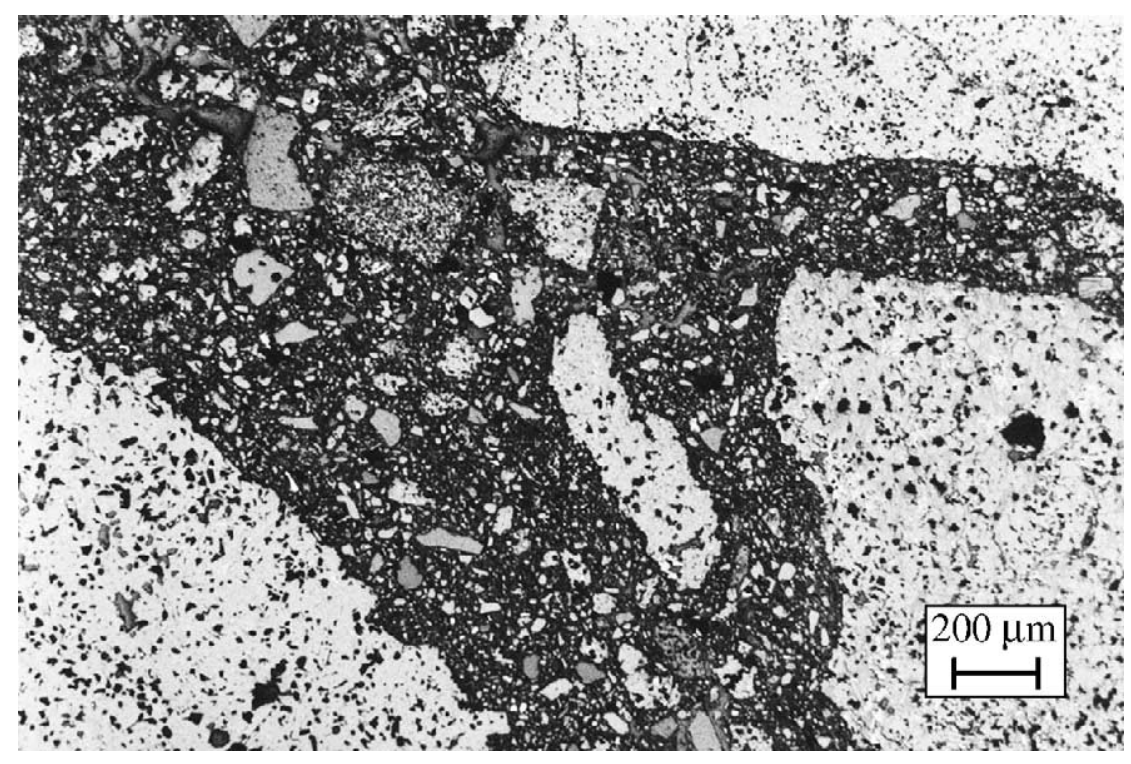

Fig. 2. Microstructure of a bauxite refractory. 
To identify the compressive behavior at a given temperature, two types of load histories are applied. First, monotonic loadings with a constant displacement rate $(V=0.3 \mathrm{~mm} / \mathrm{min})$ are performed allowing a comparison of the values of the maximum stress with that of other refractories. Then, to identify the creep behavior, a multiple step-loading path is performed $(V=0.3 \mathrm{~mm} / \mathrm{min}$; hold and relaxation; $V=$ $0.1 \mathrm{~mm} / \mathrm{min}$; hold and relaxation; $V=0.03 \mathrm{~mm} / \mathrm{min}$ ). The same types of load history are applied for the bend tests. Monotonic loadings are carried out with a constant displacement rate $(V=0.5 \mathrm{~mm} / \mathrm{min})$. Then, the tensile creep behavior is identified by a multiple step-loading path $(V=0.5 \mathrm{~mm} / \mathrm{min}$; hold and relaxation; $V=0.05 \mathrm{~mm} / \mathrm{min}$ up to failure).

Due to scatter of the experimental results of the mechanical tests and the need for a reduced number of tests to limit the cost of the experiments, first, two identical tests are performed. If both experimental results are not close enough, then a third sample is tested to find an average behavior and if needed a fourth sample.

\section{Experimental results}

The behavior under monotonic compression loads for a strain rate $\dot{\varepsilon}=8.3 \times 10^{-5} \mathrm{~s}^{-1}$ is shown in Fig. 3 for two types of refractories: namely, one called unused refractory (U-R) taken from an unused brick, which is heated for the first time, and the other one referred to as worn refractory (W-R) taken from the impregnated zone of a used brick. The behavior is strongly dependent on the temperature. The higher the temperature, the lower the maximum stress. At $1000^{\circ} \mathrm{C}$, the unused refractory exhibits a softening behavior corresponding to microcracking. The curves (1) and (2) show that the scatter of the experimental results is limited. For higher temperatures, the ductility is higher and damage is no longer observed for strains less than $0.8 \%$. The comparison of the two types of refractories at $1250^{\circ} \mathrm{C}$ shows that the change of

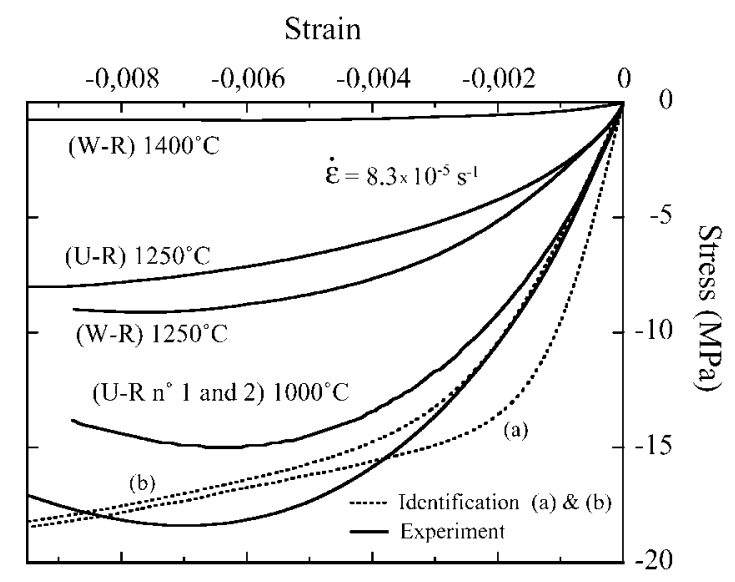

Fig. 3. Experimental results of compression tests for different temperatures and material states (U-R: unused refractory, W-R: worn refractory). Simulation of the test at $1000^{\circ} \mathrm{C}$ (a: $E=11 \mathrm{GPa}, \mathrm{b}: E=6 \mathrm{GPa}$ ).

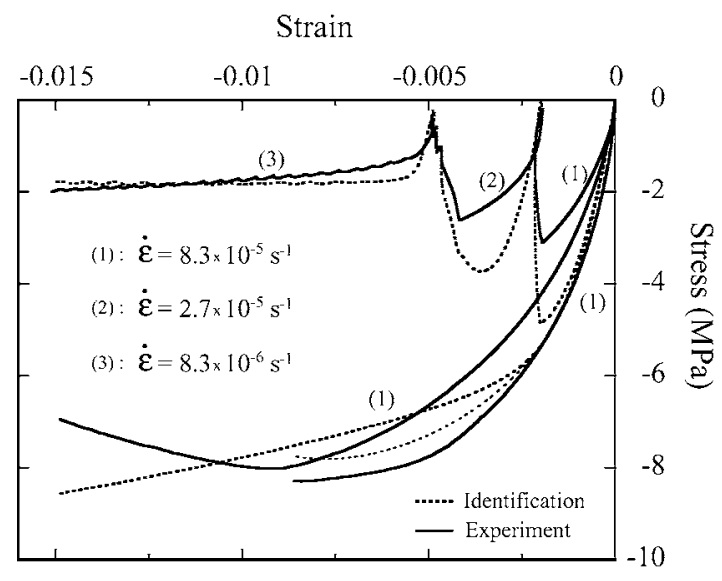

Fig. 4. Comparisons between the model and the experiments for compression test (U-R) at $1250^{\circ} \mathrm{C}$.

the microstructure of the matrix phase and the impregnation by slag have not a significant effect on the overall behavior, probably because the alumina grains transmit the load. At $1400^{\circ} \mathrm{C}$, which is a temperature close to the pyroscopic resistance of the material, the creep resistance is very low.

Fig. 4 shows a strong dependence of the material behavior on the strain rate. The slower the prescribed strain rate, the lower the maximum stress. During relaxation, the load tends towards zero, thus there is no stress threshold for the activation of the viscous behavior. Moreover, Fig. 4 shows an increase in ductility as the prescribed strain rate decreases. This tendency is confirmed by other tests carried out with a sequential load history.

Figs. 5 and 6 show load-deflection curves obtained for monotonic three-point bend tests at 1000 and $1250^{\circ} \mathrm{C}$ for the unused refractory. As already highlighted by compressive tests, a strong influence of the temperature exists. The softening behavior is more important than in compression and is also observed at the highest temperature. This part of the curves must be used with caution for the identification of the material parameters of the model because it is probably partly due to microcracking. For this reason it is not reported

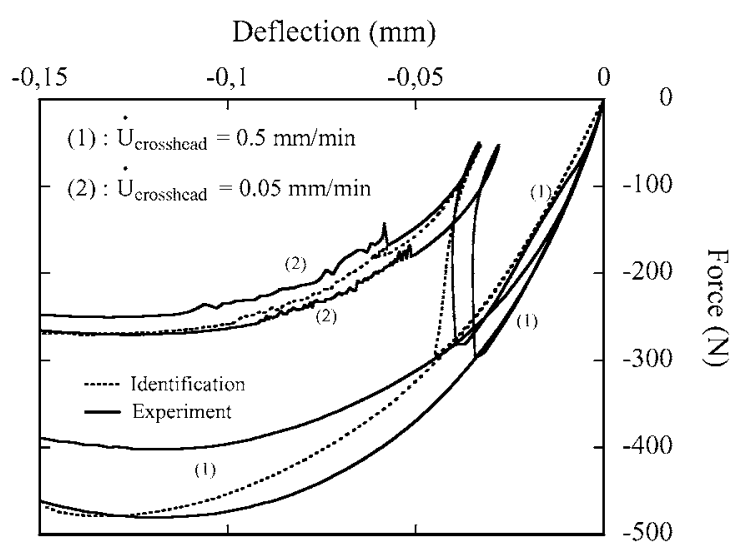

Fig. 5. Comparisons between the model and the experiments for three-point bend test (U-R) at $1000^{\circ} \mathrm{C}$. 


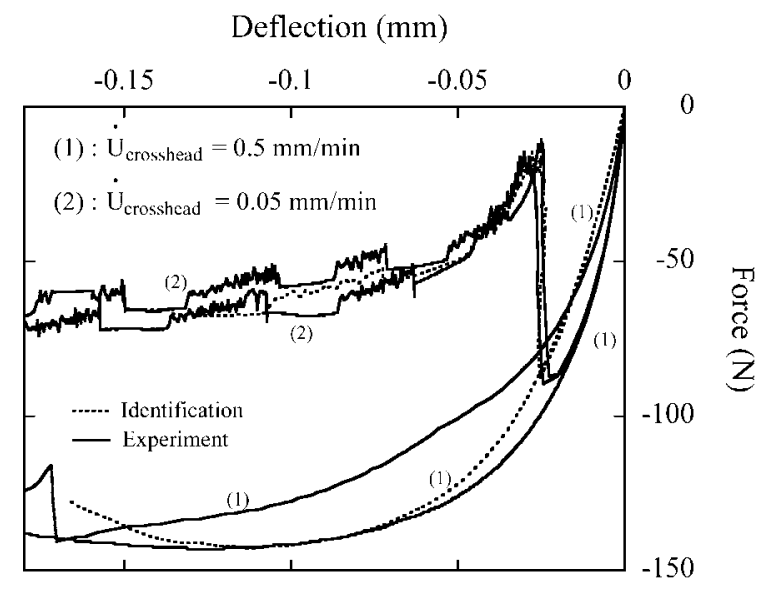

Fig. 6. Comparisons between the model and the experiments for three-point bend test (U-R) at $1250^{\circ} \mathrm{C}$.

in Figs. 5 and 6. Figs. 5 and 6 also show a strong dependence of the behavior with the strain rate: the lower the deflection rate, the lower the maximum load.

\section{Identification of the model}

Any identification of a model is always related to a validity domain. In the research project developed to understand the origin of the degradation of a bauxite refractory lining, ${ }^{18}$ the heterogeneity of the microstructure material in the brick is not controlled and many difficulties arise to collect accurate data concerning the complex stresses applied to the lining bricks. For this reason, a modelling of an average thermomechanical behavior of the refractory is sought rather than a refined one. Experimental results show that the stress threshold, above which viscoplastic behavior occurs, is very low (Figs. 4-6). Thus, the threshold stresses in tension and compression $\left(\sigma_{y}^{\mathrm{t}}\right.$ and $\left.\sigma_{y}^{\mathrm{c}}\right)$ are set to 0 . Furthermore, due to the high viscosity and the scatter, the static Young's modulus in compression and in tension (three-point bend test) is difficult to identify accurately. Consequently, it is assumed that $E_{\mathrm{c}}=$ $E_{\mathrm{t}}=E$. Since the transverse strain in compression has not been measured, the Poisson's ratio is fixed in compression and tension to the classical value for a refractory observed at room temperature $\left(v_{\mathrm{c}}=v_{\mathrm{t}}=v=0.2\right) .{ }^{1}$ The coefficient of thermal expansion $(\alpha)$ is determined by dilatometry tests. Consequently from 10 material parameters, there remain only 5 to identify.

In the first step, the identification of the set $\left(E, K_{\mathrm{c}}, n_{\mathrm{c}}\right)$ is carried out by using the compressive tests with several loading paths. In the second step, the bend test is simulated to identify the tensile contribution of the viscous strain $(E$, $\left.K_{\mathrm{c}}, n_{\mathrm{t}}\right)$ and to correct the Young's modulus. The compression tests are then simulated again. If the simulations with the new value of the Young's modulus do not fit the experimental data, the first step is performed again. Iterations are run until the solution set of parameters is obtained. During
Table 3

Material parameters for the asymmetric elastic-viscoplastic model (U-R)

\begin{tabular}{lllccc}
\hline Temperature $\left({ }^{\circ} \mathrm{C}\right)$ & $E(\mathrm{GPa})$ & $v$ & $K_{\mathrm{c}}\left(\mathrm{MPa} \mathrm{s}^{1 / n}\right)$ & $K_{\mathrm{t}}\left(\mathrm{MPa} \mathrm{s}^{1 / n}\right)$ & $n$ \\
\hline 1000 & 11 & 0.2 & 500 & 60 & 2.8 \\
1250 & 6 & 0.2 & 2600 & 300 & 1.6 \\
\hline
\end{tabular}

the optimization procedure, it has been noticed that the two creep exponents $n_{\mathrm{c}}$ and $n_{\mathrm{t}}$ are close so that the same value $n$ is chosen at a given temperature. In addition, the ratio of Norton's coefficient in compression $\left(K_{\mathrm{c}}\right)$ and tension $\left(K_{\mathrm{t}}\right)$ is virtually constant and equal to 8.5 for both temperatures. The set of parameters reported in Table 3 is a compromise solution for all the available experimental data for the unused refractory. The results of Fig. 3 and those reported by Blond $^{18}$ show that they are also valid for the worn refractory.

The set with a reduced number of material parameters proposed in Table 3 is used to simulate the compressive behavior. Fig. 4 shows both identification and experimental results for the compressive tests for the temperature $1250^{\circ} \mathrm{C}$. The identification is good at the beginning of the curve obtained from the monotonic load history. In the peak zone, results are less good because, since the model does not account for damage so that it is not able to describe the softening behavior. The simulated stress level for the multiple step-loading path test is overestimated for higher strain rates, but one has observed that this test has the lowest stress level of all compression tests performed at $1250{ }^{\circ} \mathrm{C} .{ }^{18}$ The fact that the stresses predicted by the model close to the ultimate level in the curves of the monotonic tests vary is explained by the fact that the experimental strain is prescribed in the simulation. The displacement rate of the jack was constant during the test but the strain rate was not. The dashed curve a in Fig. 3 corresponds to the identification at $1000{ }^{\circ} \mathrm{C}$. The simulation of the compressive behavior is not as good as for the previous case because the conditions $E_{\mathrm{c}}=E_{\mathrm{t}}$ and $n_{\mathrm{c}}=n_{\mathrm{t}}$ are too restrictive. More importance was given to the identification of the tensile parameters. Better results can be obtained by considering different Young's moduli and stress exponents in compression and tension. For example, when the Young's modulus in compression is reduced from 11 to $6 \mathrm{GPa}$ (Fig. 3, curve b), the identification is better for lower strain than in the previous case.

Figs. 5 and 6 show the ability of the model to reproduce the three-point bend test for two different temperatures. The values of the creep parameters $K_{\mathrm{c}}$ and $n_{\mathrm{c}}$ have only a minor role on the overall behavior of the beam. The deflection-load curve is mainly governed by the behavior of the tensile stressed zone, which is softer than the compressive zone. The tensile zone grows as the load increases because the neutral axis of the beam moves towards the upper part of the sample. The softening behavior observed in the simulation of the monotonic loading shown in Fig. 6 is due to the decrease during the load of the compressive zone, which has the highest creep resistance. 


\section{Conclusion}

As a large part of ceramics, bauxite-based refractories show an asymmetric creep behavior at high temperature; namely, a different creep behavior is observed in tension and compression. This difference is significant in bauxite refractories because of the presence of a high content of inter-granular glassy phases surrounding the oxide grains. It follows that compressive creep behavior is mainly governed by the oxide grains and the contact points between grain facets whereas the tensile creep behavior is governed by the glassy phase.

A new model is proposed to account for this different viscoplastic behavior in tension and compression. The model is built in the framework of additive stress tensor decomposition and is a three-dimensional extension of the Bingham-Norton's creep law. The shear stresses are the driving force governing the kinetics of incompressible viscoplastic strain. The use of deviatoric tensors associated, respectively, to the positive part and negative part of the stress tensor in the principal frame allows us to account for the effect of shear stress. In the present form, the model only requires 10 parameters: namely, Young's modulus $(E)$, Poisson's ratio $(v)$, threshold stress $\left(\sigma_{y}\right)$, Norton's exponent $(n)$, Norton's modulus $(K)$ in tension and compression. Furthermore, the two sets of parameters can be identified separately in tension and compression. Consequently, the set of material parameters identified in previous studies with the one-dimensional Bingham-Norton's model can be used directly without performing a new identification.

The model is implemented in a finite element code. It is identified by using compressive and three-point bend tests for bauxite-based refractories. Even though there is no validation test at disposal, the model shows a good ability to reproduce the highly asymmetric mechanical behavior. Furthermore, it is shown that for this highly viscous ceramic for which the stress levels remain low, the identification of five parameters is sufficient to obtain good results. One can even assume that the value of the ratio $K_{\mathrm{c}} / K_{\mathrm{t}}$ is nearly the same for similar types of refractories. In those cases, once the ratio $K_{\mathrm{c}} / K_{\mathrm{t}}$ has been identified for one material, as a first approximation, the same value of $K_{\mathrm{c}} / K_{\mathrm{t}}$ can be used for similar refractories so that only one type of tests has to be carried out. We suggest performing tensile or flexural tests because the tensile behavior is more sensitive than the compressive one.

This model is not able to reproduce the effects of damage accumulation in the tensile area of a flexural test for example. In the form presented here, the model does not describe the softening zone of compression and bend tests. However, this zone is not representative of the material behavior since the strains are no longer homogeneous. The model is built in the framework of additive stress tensor decomposition and it can be extended to account for damage effects using the approach proposed by Ladevèze and Lemaitre. ${ }^{30}$ However, further developments of the model increase the number of material parameters to identify, as well as the experimental data to collect.

\section{Acknowledgment}

The authors wish to thank the steel manufacturer Arcelor for financial support.

\section{References}

1. Kingery, W. D., Bowen, H. and Uhlmann, D., Introduction to Ceramics. John Wiley \& Sons, 1976.

2. Ashby, M. F. and Jones, D. R. H., Engineering Materials. Pergamon Press, 1986.

3. Lee, W. E. and Moore, R. E., Evolution of in situ refractories in the 20th century. J. Am. Ceram. Soc., 1998, 81(6), 1381-1410.

4. Cannon, W. R. and Langdon, T. G., Review: creep of ceramics. Part 1-mechanical characteristics. J. Mater. Sci., 1983, 18, 1-50.

5. Cannon, W. R. and Langdon, T. G., Review: creep of ceramics. Part 2-an examination of flow mechanisms. J. Mater. Sci., 1988, 23, $1-20$.

6. Wilkinson, D. S., Creep mechanisms in multiphase ceramic materials. J. Am. Ceram. Soc., 1998, 81(2), 275-299.

7. Blum, W., High-temperature deformation and creep of crystalline solids. In Plastic Deformation and Fracture of Materials. Series in Materials Science and Technology, ed. H. Mughrabi. VCH Publishers Inc. , 1993, pp. 360-405.

8. Ashby, M. F., A first report on deformation-mechanism maps. Acta Metall., 1972, 20, 887-897.

9. Kubo, Y., Yagi, J., Doi, K., Tanno, Y., Satoh, M. and Mori, A., Improved design of BOF lining. In Proc. Int. Conf. Refract., 1987, pp. 712-723.

10. Clavaud, B., Kiehl, J. P. and Radal, J. P., A new generation of low cement castables. In New Developments in Monolithic Refractories. Advances in Ceramics, Vol 13, ed. E. Fisher. American Ceramic Society, 1984.

11. Hübner, H., In Microstructure and Mechanical Properties of Materials, ed. E. Tenckhoff and O. Vöhringer. DGMInformationsgesellschaft, Oberursel, 1991, pp. 151-160.

12. Jin, Q., Wilkinson, D. S. and Weatherly, G. C., A model for viscous flow creep in ceramics containing secondary crystalline phases. Scripta Mater., 1999, 41, 1169-1175.

13. Ferber, M. K., Jenkins, M. G. and Tennery, V. J., Comparison of tension, compression and flexure creep for alumina and silicon nitride ceramics. Ceram. Eng. Sci. Proc., 1990, 11(7), 1028-1045.

14. Dryden, J. R., On the creep in ceramics due to a viscous grain boundary phase. J. Mech. Phys. Solids, 2000, 48, 2115-2135.

15. Hockey, B. J. and Wiederhorn, S. M., Effect of microstructure on the creep of siliconized silicon carbide. J. Am. Ceram. Soc., 1992, 75, 1822-1830.

16. Wereszezak, A. A., Ferber, M. K., Kirkland, T. P., Barnes, A. S., Frome, E. L. and Menon, M. N., Asymmetric tensile and compressive creep deformation of hot-isostatically-pressed $\mathrm{Y}_{2} \mathrm{O}_{3}$-doped- $\mathrm{Si}_{3} \mathrm{~N}_{4}$. J. Eur. Ceram. Soc., 1999, 19, 227-237.

17. Chokshi, A. H., Diffusion creep in oxide ceramics. J. Eur. Ceram. Soc., 2002, 22, 2469-2478.

18. Blond, E., Dégradation thermomécanique des réfractaires au contact de laitiers sidérurgiques. Ph.D. thesis, ENS de Cachan, France, 2003 (in French).

19. Kottada, R. S. and Chokshi, A. H., The high temperature tensile and compressive deformation characteristics of magnesia doped alumina. Acta Mater., 2000, 48, 3905-3915. 
20. Wiederhorn, S. M., Robertson, D. E., Chuang, T. J. and Chuck, L., Damage-enhanced creep in a siliconized silicon carbide: phenomenology. J. Am. Ceram. Soc., 1988, 71(7), 602-608.

21. Lemaitre, J. and Chaboche, J. L., Mechanics of Solid Materials. Cambridge University Press, 1990.

22. Berest, P., In Viscoplasticity in Rock Mechanics in GeomaterialsConstitutive Equations and Modelling, ed. F. Darve. Elsevier Science Publishing Co., 1990, pp. 239-262.

23. Chuang, T. J., Wang, Z. D. and Wu, D., Analysis of creep in a Si-SiC C-ring by finite element method. J. Eng. Mater. Tech., 1992, 114(3), 311-316.

24. Lim, H. J., Jung, J. W., Han, D. B. and Kim, K. T., A finite element model for asymmetric creep behavior of ceramics. Mater. Sci. Eng., 1997, A224, 125-130.

25. Blond, E., Schmitt, N., Hild, F., Poirier, J. and Blumenfeld, P., Thermomechanical stresses in slag-impregnated refractories. In Proc. UNITECR'01, 2001, pp. 1340-1348.

26. Germain, P., Son, Q. N. and Suquet, P., Continuum thermodynamics. ASME Trans. J. Appl. Mech., 1983, 50, 1010-1020.
27. Maugin, G. A., The Thermomechanics of Plasticity and Fracture. Cambridge University Press, 1992.

28. Coussy, O., Mechanics of Porous Continua. Wiley \& Sons Ltd., 1995.

29. Ladevèze, P., Sur une théorie de l'endommagement anisotrope. Report LMT-Cachan no. 34, 1983 (in French).

30. Ladevèze, P. and Lemaitre, J., Damage effective stress in quasiunilateral condition. In 16th IUTAM Congress, 1984.

31. Ortiz, M., A constitutive theory for the inelastic behavior of concrete. Mech. Mater., 1985, 4, 67-93.

32. Benallal, A., Billardon, R. and Doghri, I., An integration algorithm and the corresponding consistent tangent operator for fully coupled elastoplastic and damage equations. Commun. Appl. Num. Methods, 1988, 4, 731-740.

33. Abaqus, Standard Version 6.21, User's Manual. Hibbitt, Karlsson \& Sorensen, Inc., 2002.

34. Blond, E., Schmitt, N. and Hild, F., Response of saturated porous media to cyclic thermal loading. Int. J. Num. Anal. Methods Geomech., 2003, 27, 883-904. 